\title{
Visual search strategies and letter position encoding in Russian
}

Svetlana Alexeeva

Laboratory for Cognitive Studies, St. Petersburg State University, Russia

https://doi.org/10.36505/ExLing-2016/07/0003/000262

\begin{abstract}
This article reports a visual search experiment involving Cyrillic letters of the Russian alphabet. Results show that (1) the first and last letters of test arrays are detected faster than neighboring letters and the letter search function looked like M-curve; (2) letter quality influences response latencies. The results argued for parallel letter-position encoding in Russian.

Keywords: visual word recognition, visual search task, Russian, Cyrillic script.
\end{abstract}

\section{Introduction}

Previous studies postulate that identification of letters and encoding their positions within words are essential parts of written word recognition (for a review, Acha and Carreiras, 2014). There are two possibilities how we can identify letters within the words: serially (letter-by-letter) or in parallel (so-called whole-word processing) (Coltheart, 2006). One of the methods that help to shed the light on the low-level orthographic processing is visual search task (Hammond and Green, 1982, Pitchford et al., 2008).

In the task, subjects are asked to decide (press the key) whether or not a predefined target character (letter or non-letter symbol) is the part of a subsequently presented stimulus string. The position in which the cued letter appears in the string is manipulated and the response time is measured. Detection latencies for each position of stimulus strings produce a search function that is considered to reflect strategies of letter position encoding (Ktori and Pitchford, 2010).

If the search function reveals a linear component, then it is thought that serial processing comes into play (Pitchford et al., 2008). Usually, it means that the letters appearing at the beginning of the word (e.g., the $s$ and $b$ in shark) are identified faster than ones, appearing at the end (e.g., the $r$ and $k$ in shark). If the end letter is detected faster compared with the preceding letter (e.g., $k$ vs. $r$ in shark), then it is told about a parallel letter identification (Ktori and Pitchford, 2010).

Previous studies on English show that time-position dependency in five letter strings can be described by an upward-sloping M-form curve:

ExLing 2016: Proceedings of $7^{\text {th }}$ Tutorial and Research Workshop on Experimental Linguistics, 27 June - 2 July 2016, Saint Petersburg, Russia 
the first position is the fastest, but the reaction time in the second position is slower than in the third one and in the fourth position it is slower than in the fifth (Hammond and Green, 1982). The Greek language shows no latency decrease in the fifth position compared with the fourth one (Ktori and Pitchford, 2008). The result can be explained with the transparency of the Greek orthography: letters in words are processed serially in the languages with transparent orthography whereas in deep orthography languages (like in English) parallel recognition takes place (Pitchford et al., 2008).

Grapheme-phoneme correspondences in the Russian language is quite regular (but the reverse is not true) (Grigorenko, 2013). Therefore, we can predict that the serial processing dominates and time-position function would be rather line-like than an M-like curve in Russian. This paper reports a visual search experiment in Russian which investigated this claim.

\section{Method}

\section{Participants}

50 volunteers (age range 18-35 years) participated in the study. All of them were naive to the purpose of the experiment.

\section{Design and material}

We conducted an experiment with two within-subject variables: position of the target (from 1 to 5) and target-letter identity (33 Cyrillic letters). For the half of the trials the cued letter appeared within the stimulus string, for the other part, the target letter was absent. As the number of letters in the Russian alphabet is pretty high, we had five experimental lists. In each list, all 33 letters were shown as a target but only in one of 5 possible positions. We randomly assign a position for every target letter for the list 1 (e.g. $a$ in position $1,6-$ in $1,6-$ in 5 , and so on). Then we used the Latin-square principle for counterbalance letters across positions in the remaining lists. In each list, a letter was probed eight times.

We used real words as letter strings. Stimuli words were selected for every letter/position pair based on the Frequency dictionary of modern Russian (Lyashevskaya, Sharov, 2009).

\section{Procedure}

Subjects were tested individually in a quiet room. The experiment was run using E-prime software. On each trial, a lowercase target letter was presented in the centre of the screen for a duration of $1000 \mathrm{~ms}$, then the blank screen followed. After $500 \mathrm{~ms}$, the blank was replaced by a 
lowercase test array, which remained in the centre of the screen until the response. Participants were instructed to push the key '/' if they noticed the cued letter in a string of symbols and the key ' $\mathrm{z}$ ' in the opposite case. They were encouraged to make a decision as quickly and as accurately as possible.

\section{Results and discussion}

The letter search function based on mean latencies for correct responses are presented in Figure 1.

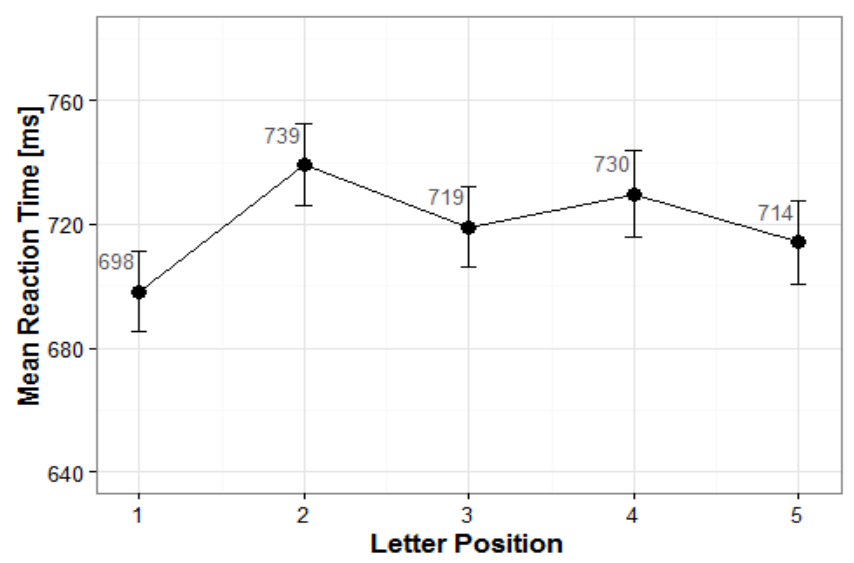

Figure 1. Visual search functions for detection latencies of correct responses across positions (ms).

We performed two linear mixed effects analyses (LMM) of the relationship between detection latencies and letter position. In both analyses, we had intercepts for subjects and items as random effects and letter identity as a fixed effect. Letter identity was coded as a sum contrast (this allowed us to compare detection latencies for each letter against the mean).

In the first analysis, we used letter position as a fixed effect, and it was coded as sliding contrast (this allowed us to compare reaction times in neighboring positions). In the second analysis letter position was entered as a covariate with cubic parameterization (this allowed us to check the significance of linear, quadratic and cubic trends). For all tests, we used the two-tailed criterion ( $t \geq 1.96)$, corresponding to a $5 \%$ error criterion for significance.

The analyses revealed that letters in the first $(t=6.51)$ and fifth positions $(\mathrm{t}=2.00)$ are detected faster than neighboring letters (in the second and fourth positions respectively). There was evidence of a significant quadratic $(t=4.68)$ and cubic components $(\mathrm{t}=-3.1)$, but a linear trend did not reach significance $(\mathrm{t}=-0.86)$. Contrary to our hypothesis the detection function was Mshaped curve like in English. So we found evidence of parallel letter 
encoding in the Russian language. We propose two possible explanations for our results: (1) the parallel/serial encoding letter strategy does not depend on transparency of the orthography; (2) the letter-string type biased the results. We selected real words for the target letter-strings, in previous studies randomly generated nonwords were used (Hammond and Green, 1982, Pitchford et al., 2008).

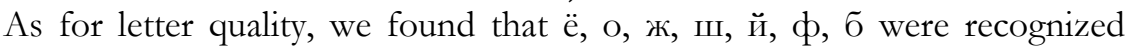
significantly faster and letters к, э, и, н, а, ь slower than the mean reaction time across all letters (see Table 1). We think that ascenders/descenders or round elements increase letter identification.

Table 1. Mean reaction times (M) [in $\mathrm{ms}$ ] and t-test values for positive detections of 33 Russian letters (L.). Effects significant indicated in bold.

\begin{tabular}{|c|c|c|c|c|c|c|c|c|c|c|c|c|c|c|}
\hline L. & $\mathrm{M}$ & $\mathrm{t}$ & $\mathrm{M}$ & L. & $\mathrm{t}$ & L. & $\mathrm{M}$ & $\mathrm{t}$ & L. & $\mathrm{M}$ & $\mathrm{t}$ & L. & M. & $\mathrm{t}$ \\
\hline $\mathrm{a}$ & 754 & -2.3 & ж & 676 & 3.1 & $\mathrm{H}$ & 754 & -2.4 & $\phi$ & 700 & 2.2 & ы & 753 & -0.8 \\
\hline 6 & 702 & 2.3 & 3 & 722 & -0.7 & $\mathrm{O}$ & 662 & 5.4 & $x$ & 699 & 1.0 & $\mathrm{~b}$ & 770 & -2.0 \\
\hline B & 717 & -0.2 & и & 743 & -2.5 & $\Pi$ & 740 & -1.9 & Ц & 749 & -0.4 & э & 752 & -2.9 \\
\hline$\Gamma$ & 733 & -1.3 & й & 706 & 2.4 & $\mathrm{p}$ & 713 & 1.1 & प & 720 & -1.7 & Ю & 721 & 0.1 \\
\hline A & 703 & 1.8 & К & 751 & -3.6 & c & 712 & 0.3 & $\amalg$ & 696 & 2.4 & Я & 733 & -1.7 \\
\hline $\mathrm{e}$ & 728 & -1.0 & $\Lambda$ & 746 & -1.6 & $\mathrm{~T}$ & 726 & -0.6 & щ & 702 & 1.2 & & & \\
\hline$\ddot{\mathrm{e}}$ & 629 & 8.3 & M & 741 & -1.1 & $y$ & 742 & -1.0 & $\mathrm{~b}$ & 714 & -0.5 & & & \\
\hline
\end{tabular}

\section{Acknowledgements}

The project is supported by Russian Science Foundation (\#14-18-02135).

\section{References}

Acha, J., and Carreiras. M., 2014. Exploring the mental lexicon. The Mental Lexicon 9. 196-231.

Coltheart. M., 2006. Dual Route and Connectionist Models of Reading: An Overview. London Review of Education 4. 5-17.

Grigorenko. E., 2013. If John were Ivan. would he fail in reading?. in: Handbook of Orthography and Literacy. Routledge. pp. 303-320.

Hammond. E.J. and Green. D.W., 1982. Detecting targets in letter and non-letter arrays. Canadian Journal of Psychology 36. 67-82.

Ktori. M. and Pitchford. N.J., 2008. Effect of orthographic transparency on letter position encoding. Language and Cognitive Processes 23. 258-281.

Ktori. M. and Pitchford. N.J., 2010. Letter position encoding across deep and transparent orthographies. in: Reading and Dyslexia in Different Orthographies. Psychology Press. pp. 69-86.

Lyashevskaya O.N. and Sharov S.A., 2009. Frequency dictionary of modern Russian. Azbukovnik. Moscow [in Russian].

Pitchford. N.J., Ledgeway. T., Masterson. J., 2008. Effect of orthographic processes on letter position encoding. Journal of Research in Reading 31. 97-116. 